\title{
IMPLEMENTASI SISTEM PENJADWALAN WISATA DI KABUPATEN TRENGGALEK BERBASIS ANDROID UNTUK MENUNJANG SMART CITY
}

\author{
Julian Sahertian ${ }^{1}$, Made Ayu Dusea Widyadara ${ }^{2}$, Frans Rega Agista ${ }^{3}$ \\ ${ }^{1,2,3)}$ Teknik Informatika, Fakultas Teknik,Universitas Nusantara PGRI Kediri \\ Jalan Ahmad Dahlan Gg. 1 No. 6, Kota Kediri \\ E-mail: juliansahertian@unpkediri.ac.id ${ }^{1}$,madedara@unpkediri.ac.id ${ }^{2}$,franz.regha19@gmail.com ${ }^{3}$
}

\begin{abstract}
ABSTRAKS
Kabupaten Trenggalek merupakan kota kecil di Jawa Timur yang memiliki potensi wisata yang sangat bagus. Berdasarkan pengamatan dan pengalaman peneliti serta hasil wawancara dengan wisatawan pada tempat wisata di Kabupaten Trenggalek didapatkan bahwa belum adanya suatu sistem penjadwalan wisata di Kabupaten Trenggalek. Akibatnya para wisatawan mengalami kesulitan dalam melakukan penjadwalan wisata yang ingin di kunjungi di wisata Kabupaten Trenggalek. Permasalahan penelitian ini adalah belum adanya rancangan sistem penjadwalan wisata di Kabupaten Trenggalek yang mampu memberikan jadwal wisata yang meliputi estimasi waktu, urutan rute dan informasi lokasi wisata sehingga mempermudah wisatawan dalam berwisata di Kabupaten Trenggalek. Hasil pengujian sistem dilakukan secara Black Box Testing. Pengujian ini dilakukan oleh 3 orang responden dari 3 Kecamatan, yaitu Kecamatan Watulimo, Kecamatan Munjungan dan Kecamatan Panggul. Dari hasil pengujian yang dilakukan, dapat disimpulkan bahwa sistem sudah berjalan sesuai dengan yang diharapkan. Secara fungsional sistem sudah dapat menghasilkan keluaran yang diharapkan.
\end{abstract}

Kata Kunci: Sistem Penjadwalan, Wisata, Trenggalek, Android, Smart City

\section{ABSTRACTS}

Trenggalek Regency is a small city in East Java that has very good tourism potential. Based on observations and experiences of researchers as well as interviews with tourists at tourist attractions in Trenggalek Regency, it was found that there is no tourism scheduling system in Trenggalek Regency. As a result, tourists have difficulty in scheduling tours that they want to visit in the tourist district of Trenggalek. The problem of this study is that there is no design of a tourist scheduling system in Trenggalek Regency that is able to provide tour schedules that include time estimates, route sequences and tourist location information making it easier for tourists to travel in Trenggalek Regency. The results of system testing are done by Black Box Testing. This test was conducted by 3 respondents from 3 districts, namely Watulimo District, Munjungan District and Panggul District. From the results of the tests conducted, it can be concluded that the system is running as expected. Functionally the system can produce the expected output.

Keywords: Scheduling System, Travel, Trenggalek, Android, Smart City

\section{PENDAHULUAN}

\subsection{Latar Belakang}

Kabupaten Trenggalek merupakan salah satu Kabupaten di Provinsi Jawa Timur yang terletak di pesisir pantai selatan Pulau Jawa dan berbatasan langsung dengan Kabupaten Ponorogo di sebelah utara, Kabupaten Tulungagung di sebelah timur, Samudera Hindia di sebelah selatan dan Kabupaten Pacitan di sebelah barat. Kabupaten Trenggalek memiliki potensi wisata yang besar dengan wisata alam yang menarik khususnya pantai, goa, air terjun, dan pegunungan yang asri. Tetapi keberadaan daya tarik wisata tersebut belum terkelola dengan baik.

Menurut hasil wawancara penulis dengan beberapa wisatawan yang berkunjung ke tempat wisata, meskipun pariwisata menjadi sektor andalan dan primadona di Kabupaten Trenggalek akan tetapi para wisatawan masih mengalami kesulitan dalam melakukan penjadwalan wisata yang ingin di kunjungi di wisata Kabupaten Trenggalek. Hal ini di karenakan masih belum adanya suatu sistem penjadwalan wisata Kabupaten Trenggalek. Penjadwalan adalah suatu proses pengalokasian sumber daya (resource) untuk mengerjakan sekumpulan tugas dalam jangka waktu tertentu (Pinedo, 2012). Tujuan dari penjadwalan adalah untuk meningkatkan penggunaan sumber daya atau mengurangi waktu tunggunya, sehinga total waktu proses dapat berkurang dan produktivitas dapat meningkat (Bedworth, 2009).

Pada penelitian ini, dikembangkan suatu sistem yang dapat melakukan penjadwalan pada tempat wisata yang ada di Kabupaten Trenggalek. Sistem yang dibuat diharapkan dapat memberikan kemudahan bagi wisatawan dalam melakukan penjadwalan wisata di Kabupaten Trenggalek yang akan dikunjungi terutama wisatawan luar Kota maupun luar Provinsi yang akan berkunjung ke Kabupaten Trenggalek. Sistem penjadwalan wisata akan diimplementasikan kedalam aplikasi mobile dan dapat dijalankan melalui Smartphone Android diharapkan semua orang dapat menggunakan karena 
smartphone Android sekarang sudah hampir semua orang memiliki dibandingkan dengan implementasi aplikasi desktop yang hanya bisa dijalankan pada komputer atau laptop.

\subsection{Rumusan Masalah}

Berdasarkan latar belakang maka rumusan masalah yang terdapat pada penelitian ini adalah bagaimana merancang dan mengimplementasikan suatu sistem penjadwalan wisata di Kabupaten Trenggalek berbasis Android untuk mempermudah wisatawan dalam melakukan penjadwalan wisata di Kabupaten Trenggalek.

\subsection{Batasan Masalah}

Batasan masalah dalam penelitian ini adalah sebagai berikut :

a. Penelitian hanya dilakukan di daerah wisata alam 3 Kecamatan di wilayah Kabupaten Trenggalek yaitu Kecamatan Watulimo, Kecamatan Munjungan, dan Kecamatan Panggul.

b. Sistem penjadwalan wisata yang akan digunakan adalah berbasis Android.

c. Aplikasi hanya menampilkan penjadwalan wisata Kabupaten Trenggalek, rute tempat wisata, dan informasi tempat wisata di Kabupaten Trenggalek.

d. Aplikasi harus terhubung dengan koneksi internet.

\section{PEMBAHASAN}

Dalam bab ini akan diuraikan tentang pembuatan Sistem Penjadwalan Wisata Kabupaten Trenggalek berbasis Android.

\subsection{Flowchart Sistem}

Berikut flowchart sistem penjadwalan wisata Kabupaten Trenggalek berbasis Android.

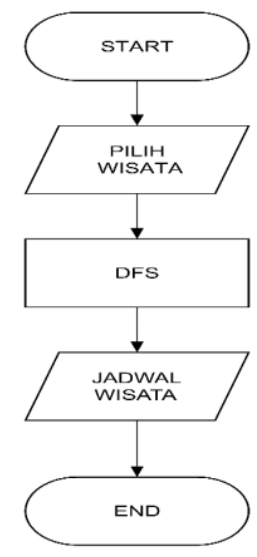

\section{Gambar 1. Flowchart Sistem}

Deskripsi Flowchart :
a. Start
Mulai menjalankan sistem

b. Pilih Wisata

Wisatawan akan memilih tempat wisata yang akan dikunjungi pada sistem penjadwalan wisata Kabupaten Trenggalek.

c. DFS

Wisata yang telah dipilih oleh wisatawan selanjutnya akan di proses oleh algoritma Depth First Search. Proses pertama dimulai dari lokasi wisatawan saat ini, selanjutnya wisata terdekat dari lokasi wisatawan, sampai lokasi terjauh dari wisatawan.

d. Jadwal Wisata

Berisi hasil penjadwalan wisata yang telah dipilih oleh wisatawan. Hasil dari penjadwalan wisata berurutan dimulai dari wisata terdekat dari posisi wisatan hingga wisata terjauh dari wisatawan.

e. End

Keluar dari sistem.

\subsection{Data Flow Diagram Level 0 (Diagram Konteks)}

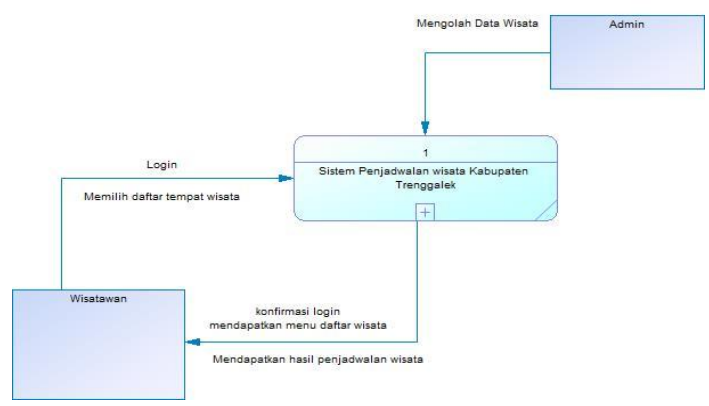

Gambar 2. DFD Level 0

Data Flow Diagram level 0 merupakan gambaran umum keseluruhan aplikasi yang dirancang. Dari Data Flow Diagram level 0 ini dapat disimpulkan bahwa didalam sistem penjadwalan wisata Kabupaten Trenggalek terdapat dua buah entitas yaitu admin dan wisatawan yang bertindak sebagai pengguna. Admin dapat melakukan input data wisata pada sistem. Sedangkan wisatawan dapat mendaftar sebagai user, memilih tempat wisata yang ingin dikunjungi pada sistem penjadwalan wisata Kabupaten Trenggalek.

\subsection{Data Flow Diagram Level 1}

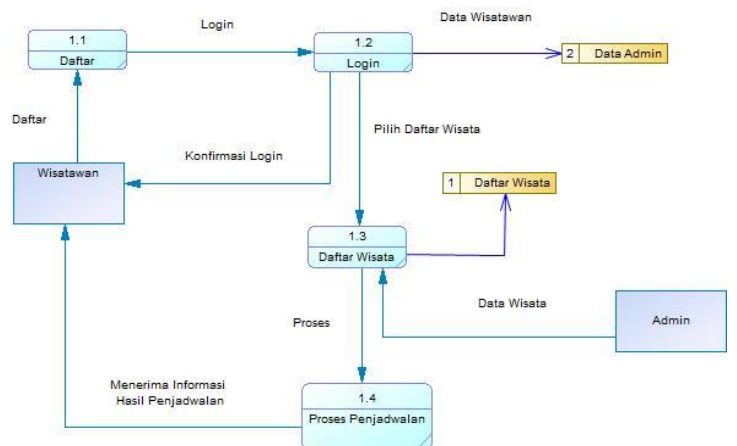

Gambar 3. DFD Level 0 
Data Flow Diagram Level 1 merupakan gambaran yang lebih terperinci dari keseluruhan aplikasi yang dirancang yang telah dijelaskan pada DFD Level 0. Pada DFD Level 1 ini dibagi menjadi 4 Proses yaitu Proses Daftar, Proses Login, Proses Daftar Wisata dan Proses Penjadwalan Wisata. Proses pertama yaitu Proses Daftar dimana wisatawan (user) terlebih dahulu mendaftar pada sistem. Setelah wisatawan (user) selesai mendaftar, selanjutnya wisatawan (user) melakukan Proses Login pada sistem. Setelah wisatawan (user) login akan masuk kedalam sistem penjadwalan wisata Kabupaten Trenggalek. Selanjutnya wisatawan (user) melakukan Proses Daftar Wisata yaitu memilih tempat wisata yang ingin dikunjungi. Setelah memilih tempat wisata yang akan dikunjungi selanjutnya wisatawan (user) melakukan Proses Penjadwalan Wisata yaitu tempat wisata yang sudah dipilih sebelumnya akan di proses oleh algoritma depth first search sehingga output dari sistem berupa penjadwalan wisata..

\subsection{Entity Relationship Diagram (ERD)}

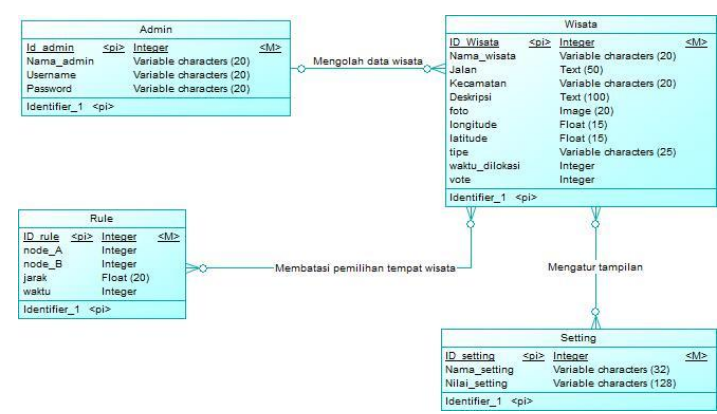

Gambar 4. ERD

Ada 4 entitas yaitu admin, wisata, rule, dan setting. Masing-masing entitas punya atribut. Hubungan antara admin dengan wisata adalah many to many, dikarenakan 1 admin dalam hal ini untuk mengelola data tempat wisata, sedangakan wisatawan (user) dapat memilih banyak tempat wisata yang ingin dikunjungi. Hubungan antara wisata dengan rule adalah many to many, dikarenakan dalam semua tempat wisata akan dibatasi oleh rule yang bertujuan untuk membedakan wisata satu dengan yang lainnya.

\subsection{Implementasi Sistem}

Pada aplikasi Sistem Penjadwalan Wisata Kabupaten Trenggalek ini, tampilan program dibuat dengan desain yang sederhana dengan tujuan untuk mempermudah penggunanya. Berikut tampilan program yang dibuat.

\section{a. Tampilan Login}

Login adalah form yang pertama kali muncul saat program dijalankan. Form login digunakan untuk masuk ke dalam sistem.

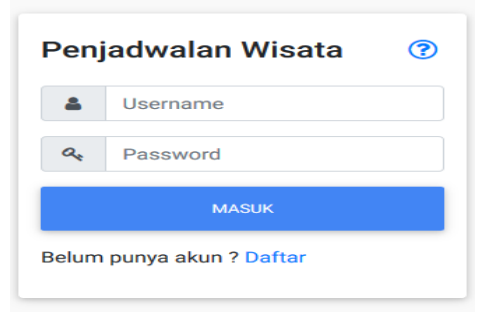

Gambar 5. Tampilan Login

b. Tampilan Daftar

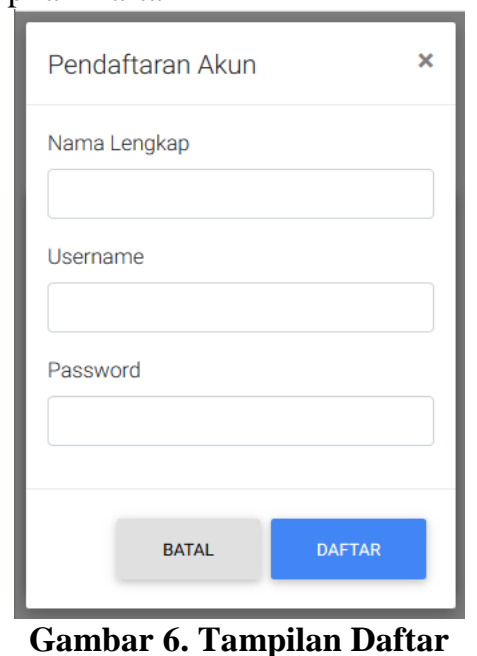

Daftar adalah form yang digunakan untuk memasukan data user agar dapat disimpan dalam sistem.

c. Tampilan Home

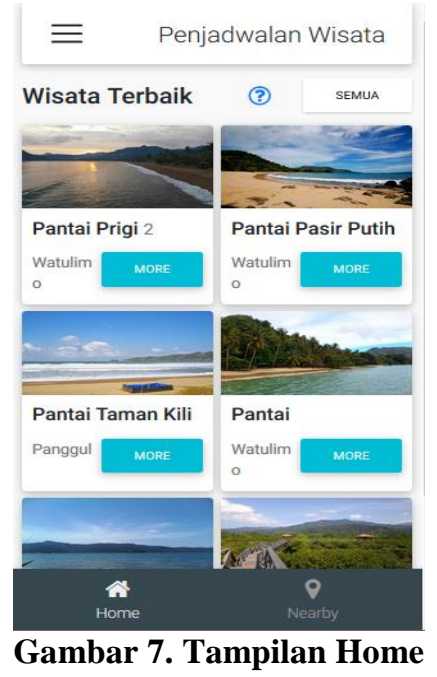

Home merupakan form modul pusat yang dapat memberikan akses kepada pengguna untuk menggunakan modul yang lain.

d. Tampilan Daftar Wisata dan Penjadwalan 


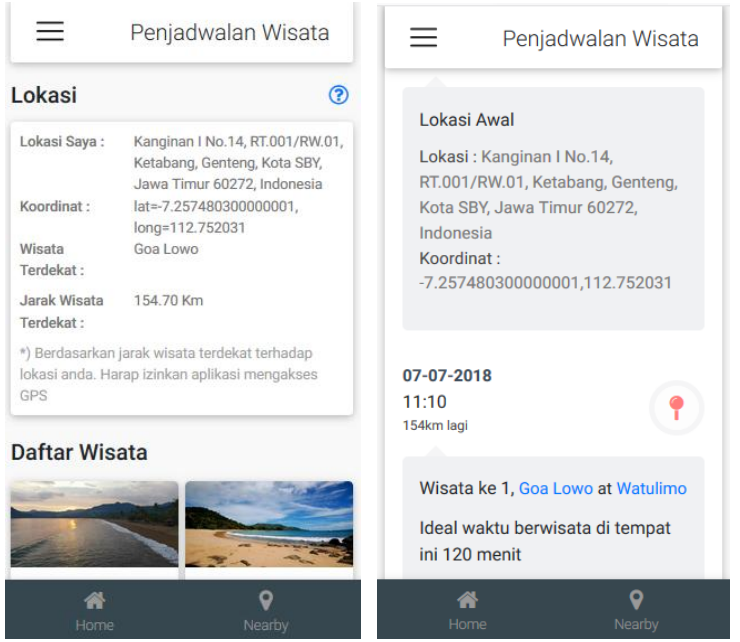

Gambar 8. Daftar Wisata dan Penjadwalan

Daftar Wisata merupakan form modul yang didalamnya terdapat menu pilih wisata serta hasil dari penjadwalan wisata yang diperoleh dari memilih tempat wisata.

e. Tampilan Nearby

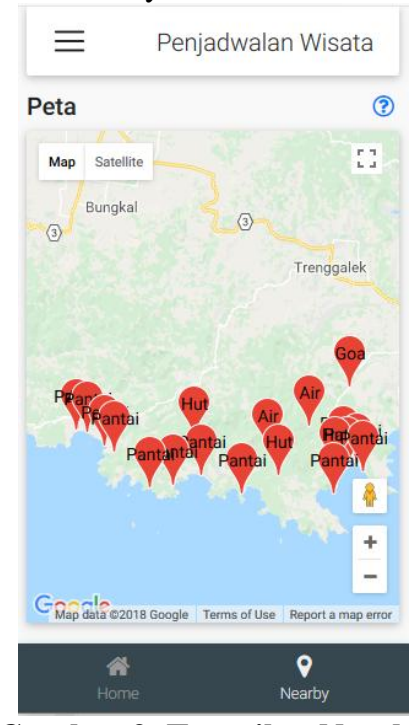

Gambar 9. Tampilan Nearby

Modul nearby merupakan modul yang didalamnya terdapat peta dari titik lokasi wisata yang ada di Kabupaten Trenggalek.

\subsection{Pengujian Sistem}

Pengujian dilakukan terhadap aplikasi untuk memastikan bahwa aplikasi berjalan dengan benar sesuai dengan kebutuhan dan tujuan yang diharapkan. Proses pengujian akan menggunakan Black Box Testing. Pengujian ini dilakukan oleh 3 orang responden dari 3 Kecamatan, yaitu Kecamatan Watulimo, Kecamatan Munjungan dan Kecamatan Panggul. Box.

Berikut hasil pengujian sistem secara Black

Tabel 1. Pengujian Tampilan Menu Daftar

\begin{tabular}{|c|l|l|l|}
\hline \multicolumn{4}{|c|}{ Kasus dan Hasil Uji } \\
\hline Masukan & Diharapkan & Pengamatan & Kesimpulan \\
\hline Klik & Sistem & Sistem & Diterima \\
Tombol & melakukan & berhasil & \\
Daftar & proses & melakukan & \\
& penyimpanan & penyimpanan & \\
& data user & data user & \\
\hline Klik & Sistem & Sistem & Diterima \\
Tombol & Melakukan & berhasil keluar & \\
Batal & Proses keluar & dari form & \\
& dari form daftar & daftar. & \\
\hline
\end{tabular}

Tabel 2. Pengujian Tampilan Menu Login

\begin{tabular}{|c|l|l|l|}
\hline \multicolumn{4}{|c|}{ Kasus dan Hasil Uji } \\
\hline Masukan & Diharapkan & Pengamatan & Kesimpulan \\
\hline Klik & Sistem & Sistem & Diterima \\
Tombol & melakukan & berhasil & \\
Login & proses login / & melakukan & \\
& masuk kedalam & proses login / & \\
& sistem. & masuk & \\
& Tersimpan. & kedalam & \\
& & sistem. & \\
\hline
\end{tabular}

Tabel 3. Pengujian Tampilan Menu Utama

\begin{tabular}{|c|c|c|c|}
\hline \multicolumn{4}{|c|}{ Kasus dan Hasil Uji } \\
\hline Masukan & Diharapkan & Pengamatan & Kesimpulan \\
\hline $\begin{array}{c}\text { Klik } \\
\text { Tombol } \\
\text { Daftar } \\
\text { Wisata }\end{array}$ & $\begin{array}{l}\text { Sistem } \\
\text { melakukan } \\
\text { proses membuka } \\
\text { form daftar } \\
\text { wisata. }\end{array}$ & $\begin{array}{l}\text { Sistem } \\
\text { berhasil } \\
\text { melakukan } \\
\text { proses } \\
\text { membuka } \\
\text { form daftar } \\
\text { wisata. }\end{array}$ & Diterima \\
\hline $\begin{array}{c}\text { Klik } \\
\text { Tombol } \\
\text { Keluar }\end{array}$ & $\begin{array}{l}\text { Sistem } \\
\text { melakukan } \\
\text { proses logout / } \\
\text { keluar dari } \\
\text { aplikasi. }\end{array}$ & $\begin{array}{l}\text { Sistem } \\
\text { berhasil } \\
\text { melakukan } \\
\text { proses logout / } \\
\text { keluar dari } \\
\text { aplikasi. } \\
\end{array}$ & Diterima \\
\hline $\begin{array}{c}\text { Klik } \\
\text { Tombol } \\
\text { More }\end{array}$ & $\begin{array}{l}\text { Sistem } \\
\text { melakukan } \\
\text { proses membuka } \\
\text { deskripsi wisata. }\end{array}$ & $\begin{array}{l}\text { Sistem } \\
\text { berhasil } \\
\text { melakukan } \\
\text { proses } \\
\text { membuka } \\
\text { deskripsi } \\
\text { wisata. }\end{array}$ & Diterima \\
\hline $\begin{array}{l}\text { Klik } \\
\text { Tombol } \\
\text { Nearby }\end{array}$ & $\begin{array}{l}\text { Sistem } \\
\text { melakukan } \\
\text { proses membuka } \\
\text { maps titik wisata } \\
\text { yang ada di } \\
\text { Kabupaten } \\
\text { Trenggalek. }\end{array}$ & $\begin{array}{l}\text { Sistem } \\
\text { berhasil } \\
\text { melakukan } \\
\text { proses } \\
\text { membuka } \\
\text { maps titik } \\
\text { wisata yang } \\
\text { ada di } \\
\text { Kabupaten } \\
\text { Trenggalek. }\end{array}$ & Diterima \\
\hline
\end{tabular}


Tabel 4. Pengujian Tampilan Daftar Wisata

\begin{tabular}{|c|c|c|c|}
\hline \multicolumn{4}{|c|}{ Kasus dan Hasil Uji } \\
\hline Masukan & Diharapkan & Pengamatan & Kesimpulan \\
\hline $\begin{array}{c}\text { Klik } \\
\text { Tombol } \\
\text { More }\end{array}$ & $\begin{array}{l}\text { Sistem } \\
\text { melakukan } \\
\text { proses membuka } \\
\text { deskripsi wisata. }\end{array}$ & $\begin{array}{l}\text { Sistem } \\
\text { berhasil } \\
\text { melakukan } \\
\text { proses } \\
\text { membuka } \\
\text { deskripsi } \\
\text { wisata. }\end{array}$ & Diterima \\
\hline $\begin{array}{c}\text { Klik } \\
\text { Tombol } \\
\text { Vote }\end{array}$ & $\begin{array}{l}\text { Sistem } \\
\text { melakukan } \\
\text { proses memilih } \\
\text { tempat wisata } \\
\text { favorit. }\end{array}$ & $\begin{array}{l}\text { Sistem } \\
\text { berhasil } \\
\text { melakukan } \\
\text { proses } \\
\text { memilih } \\
\text { tempat wisata } \\
\text { favorit. }\end{array}$ & Diterima \\
\hline $\begin{array}{c}\text { Klik } \\
\text { Tombol } \\
\text { Send }\end{array}$ & $\begin{array}{l}\text { Sistem } \\
\text { melakukan } \\
\text { proses mengolah } \\
\text { data wisata yang } \\
\text { dipilih untuk } \\
\text { ditampilkan pada } \\
\text { hasil } \\
\text { penjadwalan } \\
\text { wisata. }\end{array}$ & $\begin{array}{l}\text { Sistem } \\
\text { berhasil } \\
\text { melakukan } \\
\text { proses } \\
\text { mengolah data } \\
\text { wisata yang } \\
\text { dipilih untuk } \\
\text { ditampilkan } \\
\text { pada hasil } \\
\text { penjadwalan } \\
\text { wisata. }\end{array}$ & Diterima \\
\hline
\end{tabular}

Dari hasil pengujian yang dilakukan, dapat disimpulkan bahwa sistem sudah berjalan sesuai dengan yang diharapkan. Secara fungsional sistem sudah dapat menghasilkan keluaran yang diharapkan.

\section{KESIMPULAN}

Dalam penelitian ini telah dihasilkan Sistem Penjadwalan Wisata Kabupaten Trenggalek Menggunakan Berbasis Android untuk mempermudah wisatawan dalam melakukan penjadwalan wisata di Kabupaten Trenggalek. Dari hasil pengujian menggunakan secara Black Box Testing disimpulkan bahwa sistem sudah berjalan sesuai dengan yang diharapkan dan secara fungsional sistem sudah dapat menghasilkan keluaran yang diharapkan.

Saran untuk penelitian selanjutnya adalah sebagai berikut. Pertama Sistem aplikasi ini masih terbatas pada objek wisata alam saja yang ada di Kecamatan Watulimo, Kecamatan Munjungan dan Kecamatan Panggul. Sistem aplikasi ini dapat dikembangkan lagi dengan menambahkan objek wisata di Kecamatan lain yang ada di Kabupaten Trenggalek, objek wisata budaya, wisata religi, wisata kuliner. Kedua Sistem dikembangkan dengan menambahkan fitur-fitur yang dapat menarik wisatawan untuk menggunakan aplikasi ini seperti menambah suara pada saat navigasi ketika berkendara tanpa harus melihat Smartphone, memberi tanda suara apabila lokasi wisata yang dituju sudah dekat atau sudah sampai. Ketiga Sistem dikembangkan menggunakan algoritma tambahan ataupun menggunakan metode lain agar hasil yang didapatkan lebih optimal.

\section{PUSTAKA}

Bedworth, David D, 1987. Integrated Production Control System, Management, Analysis, Design. New York: John Wiley \& Sons.

Habib, Mochammad. 2014. Model Penjadwalan Mata Kuliah Secara Otomatis Berbasis Algoritma Depth First Search (DFS). Skripsi. Malang. Fakultas Sains dan Teknologi. Universitas Islam Negeri Maulana Malik Ibrahim Malang.

Herwanto, Arif \& Purnama, B.E., 2013. Penerapan Metode Depth First Search Pada Pencarian Rute Bus Kota Berbasis Web Mobile di Solo. Jurnal Ilmiah Go Infotech, Juni 2013, Vol. 19 No.1.

Kamil.M.I., 2015 Rancang Bangun Aplikasi Pencarian Rute Terpendek Lokasi Wisata Kuliner Kota Pontianak Berbasis Mobile. Jurnal Sistem dan Teknologi Informasi, Vol. 3 No.3.

Pinedo, M. L. 2012. Scheduling: Theory, Algorithms, and Systems. New York: Springer.

Sjukani, Moh., 2007. Struktur Data (Algoritma \& Struktur Data 2), Jakarta: Mitra Wacana Media. 